\title{
Intensidade da Cercosporiose em Mudas de Cafeeiro em Função de Fontes e Doses de Silício
}

\author{
Deila M. Santos Botelho ${ }^{1}$, Edson A. Pozza ${ }^{1}$, Adélia A. A. Pozza ${ }^{2}$, Janice G. de Carvalho ${ }^{2}$, \\ Cesar E. Botelho ${ }^{3} \&$ Paulo E. de Souza ${ }^{1}$
}

${ }^{1}$ Departamento de Fitopatologia, ${ }^{2}$ Departamento de Ciência dos Solos, ${ }^{3}$ Departamento de Fitotecnia, Universidade Federal de Lavras, Cx. Postal 37, CEP 37200-000, Lavras, MG, Fax: (035) 3829-1281, e-mail: eapozza@ufla.br

(Aceito para publicação em 01/09/2005)

Autor para correspondência: Edson Ampélio Pozza

SANTOS BOtelho, D.M., POZZA, E.A., POZZA, A.A.A., CARVAlho, J.G., BOTElHO, C.E. \& SOUZA, P.E. Intensidade da cercosporiose em mudas de cafeeiro em função de fontes e doses de silício. Fitopatologia Brasileira 30:582-588. 2005.

\section{RESUMO}

O objetivo deste estudo foi avaliar o efeito dos silicatos de cálcio e de sódio sobre a intensidade da cercosporiose (Cercospora coffeicola) em mudas de cafeeiro (Coffea arabica), cultivar Catuaí IAC 99, nas doses 0; 0,32; 0,64; 1,26 g de $\mathrm{SiO}_{2} \cdot \mathrm{kg}^{-1}$ de substrato. Foram realizadas cinco avaliações quinzenais nas quais se quantificou o número de plantas doentes, o número de folhas lesionadas por planta, o número de lesões por folha e o número total de lesões por planta. Essas avaliações foram utilizadas para construir a área abaixo da curva de progresso da doença. Ao término das avaliações, foram determinados os teores de macro, micronutrientes, silício e lignina na parte aérea das mudas de cafeeiro. A menor área abaixo da curva de progresso do total de lesões foi obtida com a dose de $0,84 \mathrm{~g} \cdot \mathrm{kg}^{-1}$ de silicato de sódio. Observouse decréscimo linear para área abaixo da curva de progresso do número de plantas doentes e aumento na concentração de lignina nas folhas até a dose de $0,52 \mathrm{~g} \cdot \mathrm{kg}^{-1}$ de silicato de sódio, enquanto no caule houve acúmulo de $\mathrm{SiO}_{2}$ até $0,53 \mathrm{~g} \cdot \mathrm{kg}^{-1}$.

Palavras-chave adicionais: Coffea arabica, Cercospora coffeicola, silicato de sódio, silicato de cálcio.

\section{ABSTRACT}

Effect of silicon doses and sources on the intensity of the brown eye spot of coffee seedlings

The objective of this work was to evaluate the effect of calcium and sodium silicate on the intensity of brown eye spot (Cercospora coffeicola) in coffee (Coffea arabica) seedlings (Catuaí IAC 99) by using doses (0; 0.32; 0.63 and 1.26 $\mathrm{g}$ of $\left.\mathrm{SiO}_{2} \cdot \mathrm{kg}^{-1}\right)$ of substrate. Five evaluations were done by counting the number of diseased plants, number of leaves with lesions, number of lesions per leaf and total number of lesions per plant. The concentration of macro, micronutrients, silicon and lignin in the leaves was determined at the end of the experiment. The lowest area under the disease progress curve of the total number of lesions was observed with $0.84 \mathrm{~g} \cdot \mathrm{kg}^{-1}$ of sodium silicate. Diseased plants were found to have a linear decrease of area under the disease progress curve and an increase in the concentration of lignin up to the dose of $0.52 \mathrm{~g} . \mathrm{kg}^{-1}$ of sodium silicate. The increase of sodium silicate and dose application into the soil up to $0.53 \mathrm{~g}^{\mathrm{kg}} \mathrm{kg}^{-1}$ decreased the concentration of $\mathrm{SiO}_{2}$ on the stem.

Additional keywords: Coffea arabica, Cercospora coffeicola, sodium silicate, calcium silicate.

\section{INTRODUÇÃO}

A cultura do café (Coffea arabica L.) no Brasil é uma das principais fontes de divisas para o país. Devido à maior competição no mercado interno e externo, além dos elevados custos de produção, existe a necessidade de se eliminar quaisquer fontes de perdas nas lavouras (Matiello et al., 2002). A ocorrência de doenças é o principal fator responsável pelas perdas desde a fase de viveiro até a produção final. No viveiro, a cercosporiose ou "mancha-deolho-pardo" causada por Cercospora coffeicola Berk. \& Cooke é uma das principais doenças responsável por desfolha e raquitismo. A intensidade da doença pode agravar-se em decorrência da deficiência hídrica prolongada e da adubação insuficiente e desequilibrada (Fernandez-Borrero et al., 1966).
A nutrição mineral é um fator ambiental passível de ser manipulado pelo homem com relativa facilidade e utilizada como complemento ou método alternativo no controle de doenças (Marschner, 1995). Entre os elementos minerais, o silício tem proporcionado resultados promissores no controle de doenças em plantas, embora não atenda aos critérios de essencialidade. O silício é considerado elemento útil ou benéfico para as plantas (Malavolta, 1980; Marschner, 1995) e segundo Epstein (1999), plantas em ambiente enriquecido com silício diferem das cultivadas com deficiência do elemento, principalmente, quanto à composição química, resistência mecânica das células, características de superfície foliar, tolerância ao estresse abiótico e a ocorrência de pragas e doenças.

Pesquisas realizadas com diversas culturas confirmaram o potencial do silício na redução da intensidade de 
doenças (Menzies et al., 1991; Bowen et al., 1992; Cherif et al., 1994; Datnoff et al., 1997; Rodrigues, 2000;). Plantas de arroz (Orysa sativa L.) cultivadas com doses crescentes desse elemento tiveram a severidade da queima-das-bainhas (Rhizoctonia solani Kühn) reduzida (Rodrigues et al., 2002). Pepineiros (Cucumis sativus L.) inoculados com Podosphaeria fuliginea (Schlecht.: Fr.) Poll., agente etiológico do oídio, e cultivados em solução nutritiva suplementada com silicato de sódio apresentaram menor número de colônias por folha, menor área da colônia e redução no poder germinativo dos conídios quando comparadas aquelas onde o silício não foi adicionado à solução nutritiva (Menzies et al., 1991). O silício também aumentou a resistência do pepineiro a Pythium ultimum Trow. Células das raízes de plantas de pepineiro infetadas por esse patógeno e que receberam a aplicação de silício, responderam de forma mais rápida a infecção, ocorrendo menor penetração devido ao acúmulo de compostos fenólicos (Cherif et al., 1994). A pulverização em folhas de videira (Vitis vinifera L.), com $17 \mathrm{mM}$ de silicato de potássio, reduziu em 14\% o número de colônias de Uncinula necator (Schw.) Burrel, agente etiológico do oídio, nas folhas inoculadas com o patógeno (Bowen et al., 1992). De acordo com os autores, a redução ocorreu pelo efeito inibitório do silício na germinação do conídio. No entanto, para o cafeeiro os efeitos do silício sobre as doenças ainda não estão perfeitamente elucidados.

O objetivo do presente trabalho foi avaliar o efeito de diferentes doses dos silicatos de cálcio e de sódio na redução da intensidade da cercosporiose e sua relação com a nutrição mineral de mudas de cafeeiro.

\section{MATERIAL E MÉTODOS}

O experimento foi conduzido no viveiro de mudas do Departamento de Fitopatologia da Universidade Federal de Lavras, no período de agosto de 2001 a maio de 2002. O delineamento experimental utilizado foi o de blocos casualizados, com quatro repetições, arranjado em fatorial 2X4, com duas fontes de silício, quais sejam, silicato de cálcio $\left(\mathrm{CaO}-18 \%, \mathrm{SiO}_{2}-63 \%\right)$ e silicato de sódio $\left(\mathrm{Na}_{2} \mathrm{O}-\right.$ $18 \%, \mathrm{SiO}_{2}-63 \%$ ), em quatro doses, $0 ; 0,5 ; 1$ e 2 g. $\mathrm{Kg}^{-1}$. Essas doses corresponderam a 0; 0,32; 0,63 e 1,26 g de $\mathrm{SiO}_{2}$ por quilo de substrato ou $0 ; 0,12 ; 0,24$ e $0,48 \mathrm{~g} \mathrm{de} \mathrm{Si.kg}^{-1}$, respectivamente. A unidade experimental foi composta de nove plantas por repetição.

\section{Plantio das mudas}

A semeadura do cultivar de café Catuaí Vermelho IAC 99 foi realizada diretamente em sacos de polietileno $(11 \times 20 \mathrm{~cm})$ contendo substrato constituído por $3001 \mathrm{de}$ esterco, 7001 de terra de subsolo de um Latossolo Vermelho distroférrico (LVd), com teor de silício 11,6 mg. $\mathrm{kg}^{-1}$, adubados com $5 \mathrm{~kg}$ de superfosfato simples e $500 \mathrm{~g}$ de cloreto de potássio por $\mathrm{m}^{-3}$ de substrato (CFSEMG, 1999). Todo o substrato foi fumigado com brometo de metila $\left(150 \mathrm{ml} . \mathrm{m}^{-3}\right.$ de substrato). Os silicatos foram misturados ao substrato de forma homogênea, conforme os tratamentos, antes do enchimento dos saquinhos. As plântulas foram obtidas em bandejas contendo areia lavada. O transplantio para os saquinhos foi realizado no estádio de "palito de fósforo". As plantas foram mantidas em viveiro coberto com sombrite a $70 \%$ de intensidade luminosa e irrigadas diariamente. Para o controle do bicho mineiro foi utilizado o inseticida Ethion, o qual foi aplicado uma única vez, quando as plantas apresentavam seis pares de folhas.

\section{Inoculação com Cercospora coffeicola}

As mudas foram inoculadas com C. coffeicola quando apresentavam três pares de folha, aproximadamente 150 dias após o plantio. Para o preparo do inóculo, folhas naturalmente infetadas com $C$. coffeicola, coletadas em cafezais no campus da Universidade Federal de Lavras, foram submetidas à câmara úmida por $48 \mathrm{~h}$. Com auxílio de pincel e água, os conídios foram retirados, quantificados em câmara de 'Newbauer' e ajustados para concentração de $1,5 \times 10^{4}$ conídios. $\mathrm{ml}^{-1}$ conforme metodologia descrita por Pozza et al. (2000).

A suspensão foi aplicada em todas as folhas da planta com pulverizador 'De Vilbiss' $\mathrm{n}^{\circ} 15$, até o ponto de escorrimento. Foram realizadas três inoculações, com intervalo de sete dias, para assegurar a infecção pelo patógeno.

\section{Avaliação da intensidade da cercosporiose}

A intensidade da cercosporiose foi quantificada por cinco avaliações quinzenais da incidência e da severidade. A incidência foi avaliada pelo número de plantas com sintomas da doença na parcela e pelo número de folhas com lesões por planta. A severidade foi avaliada pela contagem do número de lesões por folha, número total de lesões por planta e da área foliar lesionada. Para obter a área foliar lesionada, utilizou-se plástico de transparência, no qual as lesões foram desenhadas com caneta de retroprojetor. Esse desenho foi escaneado e exportado para o programa 'Image Tool', para mensurar a área foliar lesionada. A área foliar total de cada planta foi determinada por análise não destrutiva, com medidor laser de área foliar (Laser Area Meter CI-203 - CID Incorp.). De posse destes dados, obtevese a porcentagem de área foliar lesionada. Para as variáveis incidência e severidade ao longo do tempo, foram calculadas a área abaixo da curva de progresso do número de plantas doentes (AACPPD), do número de folhas lesionadas (AACPNFL), do número total de lesões (AACPTL) e área abaixo da curva de progresso do número de lesões por folha (AACPLF), de acordo com equação citada por Campbell \& Madden (1990).

Após o término das avaliações, todas as plantas da parcela foram colhidas, separadas em folhas e caule, os quais foram lavados, secos em estufa de circulação de ar forçado a $65{ }^{\circ} \mathrm{C}$ e moídos para posterior análise nutricional e determinação das concentrações de silício e lignina na parte aérea dos diferentes tratamentos. 


\section{Quantificação do teor de silício}

Procedeu-se a análise do teor de silício, tanto no caule quanto nas folhas, segundo o método colorimétrico do azul de molibdênio proposto por Furlani \& Galo (1978). A metodologia envolveu três etapas: incineração do material a $500{ }^{\circ} \mathrm{C}$ por 30 min em cadinho de níquel; dissolução do $\mathrm{SiO}_{2}$ com solução de $\mathrm{NaOH}$ a $10 \%$ e novo aquecimento nas mesmas condições por $20 \mathrm{~min}$; dissolução do silicato de sódio formado com água destilada no próprio cadinho. O extrato final foi obtido transferindo-se alíquotas variáveis de 1 a $5 \mathrm{ml}$ dos cadinhos para recipientes plásticos com volume final completado para $50 \mathrm{ml}$. A dosagem de silício foi feita por leituras colorimétricas $(810 \mathrm{~nm})$ em alíquotas de $50 \mathrm{ml}$, contendo, além do extrato, soluções de $\mathrm{H}_{2} \mathrm{SO}_{4}$, molibdato de amônio, ácido oxálico e ácido ascórbico, tendo os teores de silício sido calculados com base em curva padrão preparada com $\mathrm{Na}_{2} \mathrm{SiO}_{3}$ padrão primário, sendo em seguida corrigidos para silício acumulado na matéria seca da parte aérea.

\section{Quantificação do teor de lignina nas folhas}

Para avaliação do teor de lignina na parte aérea utilizou-se o método do permanganato de potássio, citado por Silva (1981). As amostras de tecido vegetal foram oxidadas por meio de solução tamponada de ácido acético $(500 \mathrm{ml})$ e permanganato de potássio $(50 \mathrm{~g})$, contendo ferro trivalente $(6 \mathrm{~g})$ e prata monovalente $(0,15 \mathrm{~g})$ como catalisadores. Os óxidos de ferro e manganês depositados foram dissolvidos em solução alcóolica (solução de desmineralização) contendo os ácidos oxálico (50 g) e clorídrico $(50 \mathrm{ml})$. A lignina foi calculada por diferença de peso, após estes tratamentos.

\section{Análise nutricional}

A determinação dos teores de N, P, K, Ca, Mg, S, B, $\mathrm{Cu}, \mathrm{Fe}, \mathrm{Mn}$ e $\mathrm{Zn}$ de cada tratamento foi realizada segundo a metodologia descrita por Malavolta et al. (1997).

\section{Análise estatística}

A análise de variância foi realizada em esquema fatorial utilizando o programa Sisvar ${ }^{\circledR}$ - versão 4.3 (Build 4.2). Procedeu-se a análise de regressão quando o efeito de dose foi significativo. No caso de fontes, a própria significância do teste $\mathrm{F}$, indicou a diferença entre as mesmas.

\section{RESULTADOS E DISCUSSÃO}

A AACPPD apresentou diferença significativa para as doses de silício. Observou-se decréscimo linear de 10,8\% na porcentagem de plantas doentes com aumento das doses de $\mathrm{SiO}_{2}$ aplicadas ao substrato (Figura 1A). Na maior dose de silício (1,26 g. $\mathrm{kg}^{-1}$ de substrato) ocorreu a menor AACPPD. Os mecanismos pelos quais o silício pode conferir resistência à determinada doença podem ser por barreiras estruturais como o acúmulo desse elemento na parede das células da epiderme e da cutícula ou acúmulo no local de penetração do patógeno (Bowen et al., 1992; Epstein, 1999; Rodrigues et al., 2003), ou por ativar barreiras químicas e bioquímicas da planta (Bélanger et al., 2003; Rodrigues et al., 2003). Para o cafeeiro, esses mecanismos de resistência ainda não foram totalmente esclarecidos. Pozza et al. (2004) observaram que o aumento da resistência do cafeeiro à cercosporiose deveu-se ao maior espessamento da cutícula e ao aumento da absorção de micronutrientes pelas plantas tratadas com silício. Estes autores obtiveram imagens em microscopia eletrônica de varredura, nas quais observaram a presença de uma cutícula mais espessa cobrindo parcialmente os estômatos na superfície inferior da folha das mudas de cafeeiro tratadas com silicato de cálcio no solo. Os autores observaram que o espessamento da cutícula, devido principalmente à formação de uma camada de cera epicuticular mais espessa, dificultou a penetração diretamente através da cutícula ou por estômatos. Essa camada de cera epicuticular pode ter tornado a superfície mais hidrofóbica,
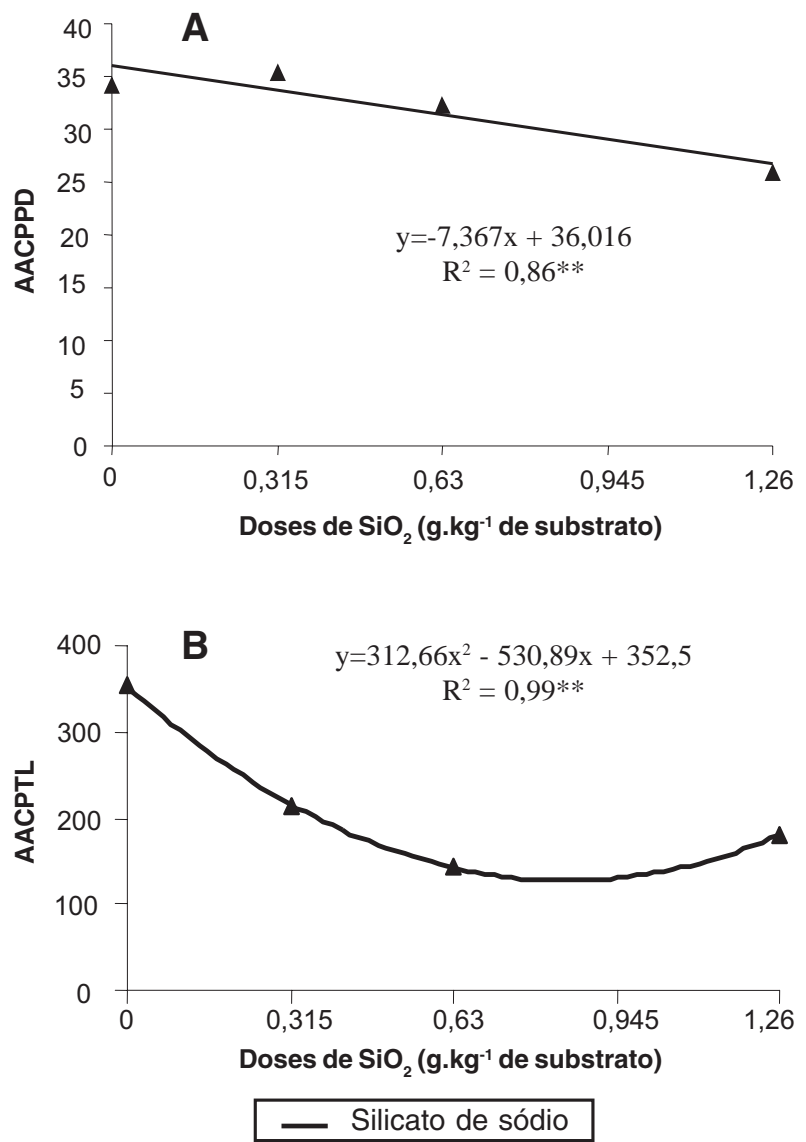

FIG. 1 - Área abaixo da curva de progresso do número de plantas doentes (AACPPD) (A) e área abaixo da curva de progresso do número total de lesões (AACPTL) (B) para a mancha de olho pardo do cafeeiro (Coffea arabica), em função das doses crescentes de silício aplicadas ao substrato. ** Significativo, a $1 \%$ de probabilidade, pelo teste $\mathrm{F}$. 
impedindo a formação do filme de água, importante para os processos vitais da patogênese como a germinação e a penetração, além de permitir o acúmulo de substâncias antifúngicas na cutícula, conforme Pascholati \& Leite (1995). Esses autores também citaram exemplos de patossistemas, como Fusarium solani f.sp. pisi (F.R. Jones) Snyder \& Hansen da ervilha (Pisum sativum L.) e Colletotrichum gloesporioides (Penz.) Penz. \& Sacc. do mamoeiro (Carica papaya L.), em que a maior espessura da cutícula reduziu a penetração dos fungos, podendo ter ocorrido o mesmo nesse experimento.

A área abaixo da curva de progresso do número de folhas lesionadas por planta e a área abaixo da curva de progresso do número de lesões de $C$. coffeicola por folha não diferiram com adição de silício ao substrato. Em outros trabalhos, com avaliação dessas duas variáveis para outros nutrientes ( $\mathrm{N}, \mathrm{K}$ e $\mathrm{Ca}$ ), as diferenças também não foram significativas, provavelmente devido ao fato de poucas manchas da cercosporiose provocarem a queda das folhas, impossibilitando a análise correta dessas variáveis (Pozza et al., 2000; Garcia Júnior et al, 2003).

Houve interação entre a fonte e as doses de silício para a área abaixo da curva de progresso do total de lesões por planta (AACPTL). Observou-se o efeito somente do silicato de sódio na redução do total de lesões por planta (Figura 1B). O menor valor da AACPTL foi obtido na dose 0,84 g. $\mathrm{kg}^{-1}$ de substrato. Rodrigues et al. (2002), em plantas de arroz, também observaram e decréscimo do número total de lesões da queima-das-bainhas tratadas com diferentes doses de silicato de cálcio, tendo como fonte a 'Wollastonita'. Os autores atribuíram esse resultado não apenas à formação de barreira física abaixo da epiderme, mas também à possível indução dos mecanismos de resistência no hospedeiro. De acordo com Chérif et al. (1994), a indução é expressa por reações em cadeia de várias mudanças bioquímicas associadas, responsáveis por limitar a ação do patógeno. Essa característica explica a não especificidade da resistência induzida pelo silício, em várias doenças.

O teor de silício nas folhas não foi significativamente influenciado pelos tratamentos utilizados. Bezerra (2000), em trabalho conduzido com cafeeiros adultos visando verificar o efeito do silício na intensidade da ferrugem (Hemileia vastatrix Berk. \& Br.), também não encontrou diferença nos teores de silício nas folhas.

O teor de silício no caule foi influenciado pelas fontes e doses de silício estudadas. A concentração de silício foi maior com a fonte silicato de sódio (Tabela 1), devido a maior solubilidade do produto, comparado ao silicato de cálcio, favorecendo maior absorção do elemento. Com relação às doses, o teor de silício no caule reduziu até a dose de $0,53 \mathrm{~g} \cdot \mathrm{kg}^{-1}$ com posterior incremento (Figura 2A).

A adição de silício ao substrato proporcionou aumento do teor de lignina nas plantas, até a dose de $0,52 \mathrm{~g} \cdot \mathrm{kg}^{-1}$ de $\mathrm{SiO}_{2}$ (Figura 2B). Nas doses menores, o silício, possivelmente, distribuiu-se melhor e foi translocado para as folhas, promovendo aumento na quantidade de lignina e
TABELA 1 - Teor de cálcio $\left(\mathrm{g} \cdot \mathrm{kg}^{-1}\right)$ nos tecidos foliares e silício no caule $\left(\mathrm{mg} \cdot \mathrm{kg}^{-1}\right)$ em mudas de cafeeiro (Coffea arabica)

\begin{tabular}{lcc}
\hline \hline Fontes de silício & $\begin{array}{c}\text { Teor de Ca nas } \\
\text { folhas }^{\mathbf{a}}\end{array}$ & $\begin{array}{c}\text { Teor de Si no } \\
\text { caule }^{\mathbf{a}}\end{array}$ \\
\hline Silicato de sódio & $11,21 \mathrm{~B}$ & $0,65 \mathrm{~A}$ \\
Silicato de cálcio & $11,75 \mathrm{~A}$ & $0,44 \mathrm{~B}$ \\
\hline
\end{tabular}

${ }^{\text {a }}$ Médias seguidas de letras diferentes nas linhas diferem estatisticamente entre si pelo teste $F(P \leq 0,05)$

favorecendo a redução da intensidade da cercosporiose nas mudas de cafeeiro (Figuras 1A e 1B). Com aumento das doses, ocorreu acúmulo no caule e redução na translocação do silício para a folha, resultando na queda da concentração de lignina na folha (Figuras 2A e 2B), porém ainda em quantidade necessária para proporcinar redução na intensidade da doença. Plantas de pepino suplementadas com silício apresentaram aumento na atividade das enzimas precursoras da lignina, a peroxidase e a polifenoloxidase (Chérif et al., 1994). A lignina é um componente importante na resistência de plantas a patógenos, pois limita a ação
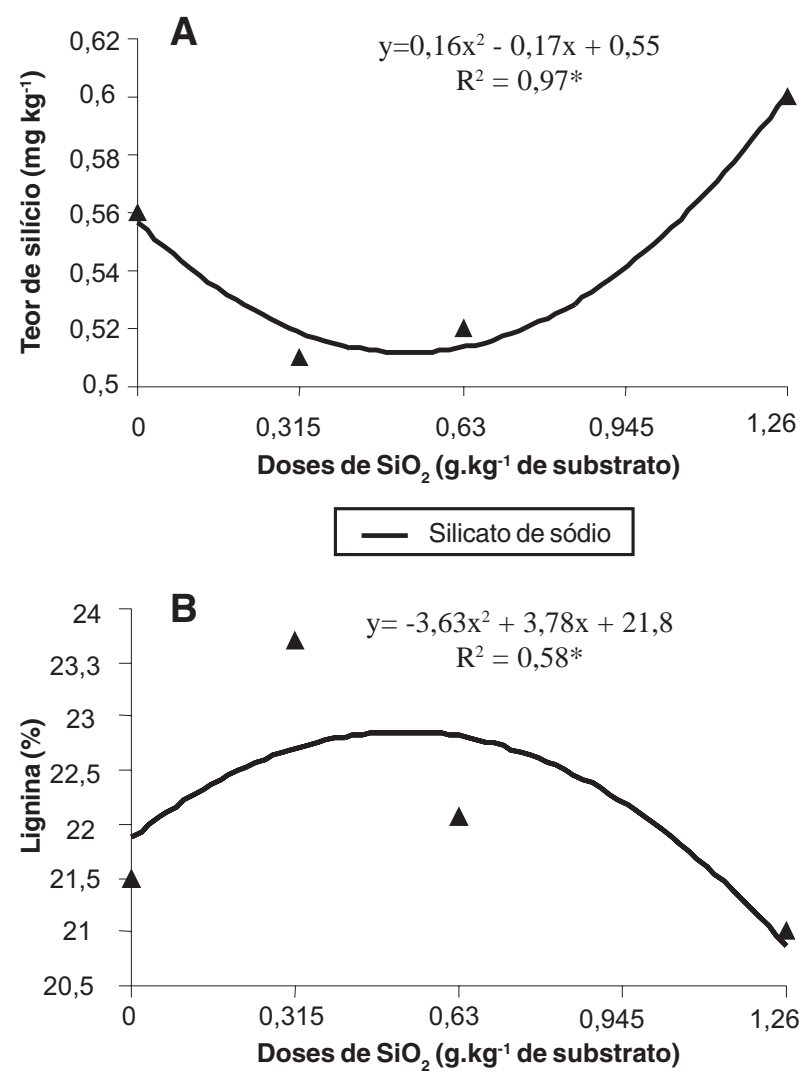

FIG. 2 - Teor de silício no caule (A) e de lignina nos tecidos foliares (B) de cafeeiro (Coffea arabica)em função das doses de silício (g.kg-1 de substrato). * significativo, a 5\% de probabilidade, pelo teste F. 
destes pela formação de barreira física.

A aplicação de silicato de sódio e de cálcio tem efeito corretivo da acidez do solo, além de elevar o $\mathrm{pH}$ próximo da rizosfera das plantas (Khalid et al., 1978). Fontes de silicato de cálcio provenientes de siderurgia, 'Wollastonita', silicato de magnésio e termofosfato foram avaliadas por Korndörfer \& Gascho, 1999, em quatro tipos de solo. Todas as fontes aumentaram o pH dos solos. Conforme Pozza (2004), esse aumento no $\mathrm{pH}$ promovido pelo silicato, influencia a absorção dos nutrientes essenciais e aumenta a eficiência nutricional das plantas. Neste experimento, a aplicação do silício ao substrato afetou a disponibilidade de cálcio, nitrogênio, magnésio, ferro e manganês para as plantas. Entretanto, não houve influência nas concentrações de $\mathrm{P}$, $\mathrm{K}, \mathrm{S}, \mathrm{B}$ e de Zn.

A concentração de cálcio nos tecidos foliares foi influenciada por ambas as fontes e as doses de silicato, não ocorrendo interação significativa. A maior concentração de cálcio foi encontrada quando a fonte utilizada foi o silicato de cálcio (Tabela 1). Esse resultado é justificado pela composição da fonte, com $18 \%$ de $\mathrm{CaO}$. Com relação às doses, ocorreu aumento na concentração até a dose de 0,68 g. $\mathrm{kg}^{-1}$ de $\mathrm{SiO}_{2}$ e posteriormente diminuiu (Figura 3A), coincidindo com a redução na AACPTL (Figura 1B). A suscetibilidade de plantas a alguns patógenos é inversamente relacionada com o teor de cálcio nos tecidos vegetais. Este nutriente é essencial para formar poligalacturonatos de cálcio, requeridos na lamela média para estabilidade da parede celular (Marschner, 1995). O aumento nas doses de cálcio reduziu a intensidade da cercosporiose em mudas de cafeeiro em solução nutritiva (Garcia Júnior et al, 2003).

O teor de nitrogênio foi influenciado significativamente pelas doses de $\mathrm{SiO}_{2}$. Observou-se decréscimo na concentração do nutriente até a dose de 0,85 g. $\mathrm{kg}^{-1}$, aumentando após esta dose (Figura 3B). Resultados semelhantes foram encontrados por Deren (1997), em plantas de arroz tratadas com silício. O teor de magnésio foi afetado significativamente pela interação fonte $\mathrm{x}$ dose. A concentração de magnésio reduziu até a dose de 0,72 g.kg${ }^{1}$ de silicato de cálcio e depois tendeu a aumentar. Para o silicato de sódio, o teor de magnésio reduziu até a dose de 0,30 g. $\mathrm{kg}^{-1}$ e, após esta dose, aumentou (Figura 3C). Na literatura existem referências ao "antagonismo" entre magnésio e cálcio; em que o aumento na concentração de um no meio implica na diminuição da absorção do outro (Malavolta, 1980).

Os teores de ferro e manganês foram influenciados pelas doses de $\mathrm{SiO}_{2}$. Com o aumento das doses de $\mathrm{SiO}_{2}$ observou-se decréscimo nos teores de ferro até $0,52 \mathrm{~g} \cdot \mathrm{kg}^{-1} \mathrm{e}$ acréscimo nos teores de manganês até $0,48 \mathrm{~g} \cdot \mathrm{kg}^{-1}$ (Figuras 4A e 4B). A ausência do íon ferro nas células resulta na maior suscetibilidade das plantas às doenças devido à menor síntese de compostos antifúngicos (Marschner, 1995), responsáveis por inibir a ação de patógenos. Porém, nesse experimento os teores de ferro foram suficientes para nutrir a planta. A redução nos teores de manganês observada com
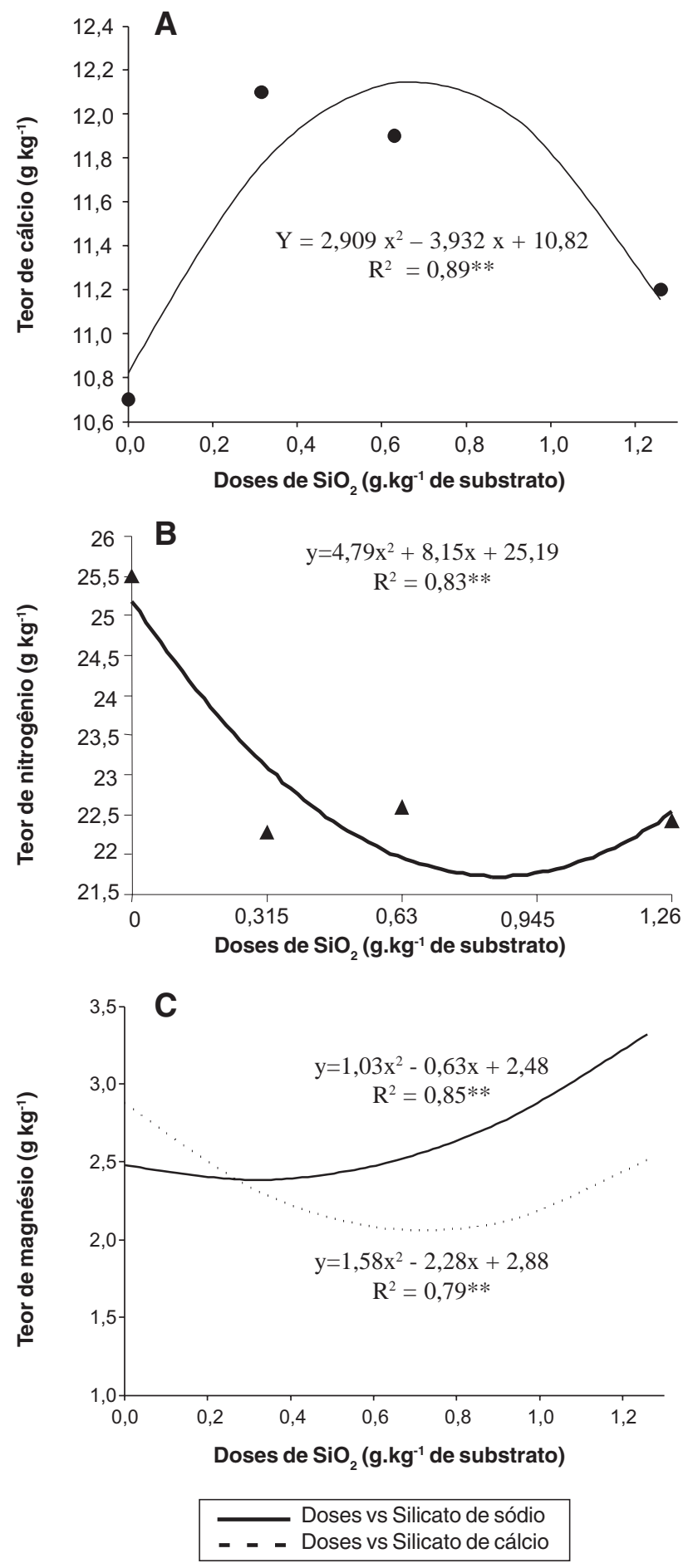

FIG. 3 - Concentrações de cálcio (A), nitrogênio (B) e magnésio (C) em tecidos foliares do caffeiro (Coffea arabica) em função das doses de óxido de silício utilizadas. ** Significativo, a $1 \%$ de probabilidade pelo teste $\mathrm{F}$.

o aumento das doses de silício é explicada pela presença do $\mathrm{Ca}^{+2}$ e do $\mathrm{Na}^{+}$na composição dos silicatos utilizados, que 
competem pelo mesmo sítio de absorção do manganês (Malavolta, 1980). Esse nutriente afeta a enzima fenilalaninamonialiase (PAL) e estimula peroxidases requeridas na biossíntese de lignina, componente importante na resistência de plantas a patógenos (Marschner, 1995).
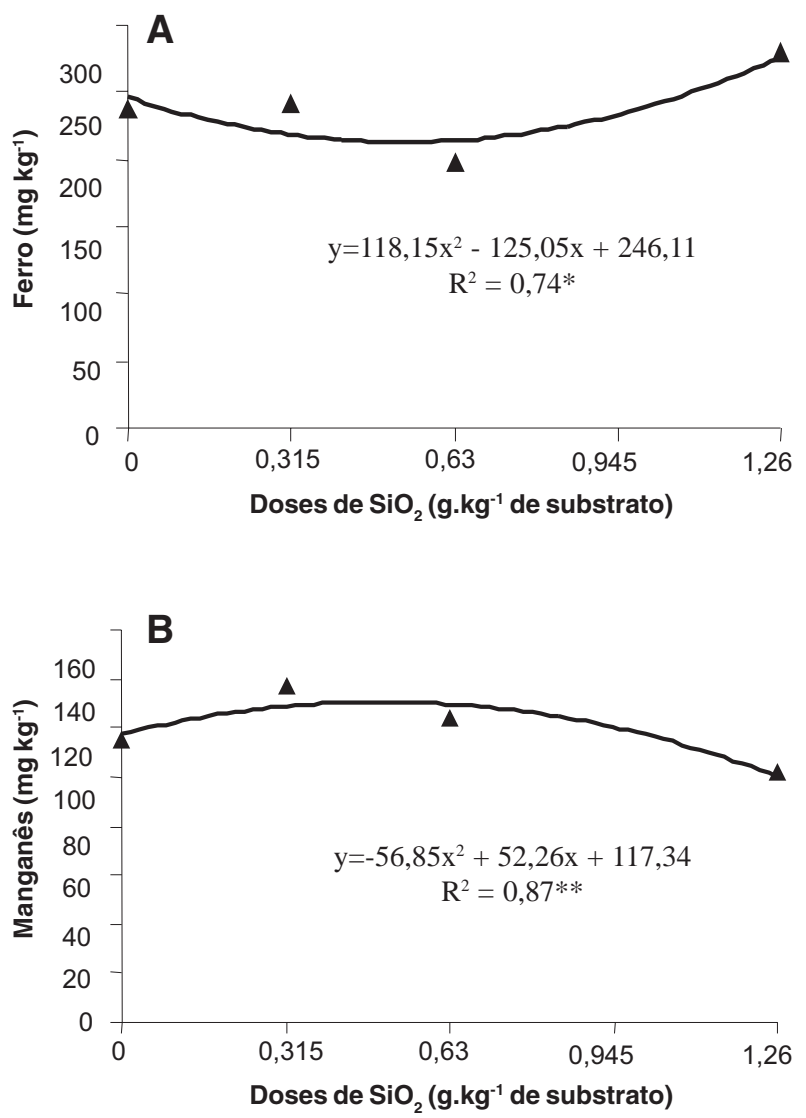

FIG. 4 - Concentrações de ferro (A) e de manganês (B) em folhas de cafeeiro (Coffea arabica) em função das doses de óxido de silício utilizadas. **,* Significativo a $1 \%$ e a $5 \%$ de probabilidade pelo teste $\mathrm{F}$.

\section{REFERÊNCIAS BIBLIOGRÁFICAS}

BÉLANGER, R.R., BENHAMOU, N. \& MENZIES, J.G. Mineral nutrition in the management of plant diseases. Phytopathology. 93:402-412. 2003.

BEZERRA, H.R. Estudo do silício no controle da ferrugem e na produtividade do cafeeiro (Monografia em Agronomia). Universidade Federal de Uberlândia, 2000.

BOWEN, P., MENZIES, J. \& EHRET, D. Soluble silicon sprays inhibit powdery mildew development on grape leaves. Journal of the American Society for Horticultural Science 117:906-912. 1992.

CAMPBELL, C.L. \& MADDEN, L.V. Introduction to plant disease epidemiology. New York, 1990.
CHÉRIF, M., ASSELIN, A. \& BÉLANGER, R.R. Defense responses induced by soluble silicon in cucumber roots infected by Pythium spp. Phytopathology 84:236- 242. 1994.

COMISSÃO DE FERTILIDADE DO SOLO DO ESTADO DE MINAS GERAIS. Recomendações para o uso de corretivos e fertilizantes em Minas Gerais: 5ª Aproximação. Viçosa, MG. 1999.

DATNOFF, L.E., DEREN, C.W. \& SNYDER, G.H. Silicon fertilization for disease management of rice in Florida. Crop Protection 16:525-531. 1997.

DEREN, W. Changes in nitrogen and phosphorus concentrations of silicon-fertilized rice grown on organic soil. Journal of Plant Nutrition 20:765-771. 1997.

EPSTEIN, E. Silicon. Annual Review of Plant Physiology and Plant Molecular Biology 50:641-664. 1999.

FERNANDEZ-BORRERO, O., MESTRE, A.M. \& DUQUE, S.L. Efecto de la fertilizacion en la incidência de la mancha de hierro (Cercospora coffeicola) en frutos de café. Cenicafé 17:5-16. 1966.

FURLANI, P.R. \& GALLO, J.R. Determinação de silício em material vegetal, pelo método colorimétrico do "azul-demolibdênio" Bragantia 37:V- XI. 1978.

GARCIA JÚNIOR, D., POZZA, E.A., POZZA, A.A.A., SOUZA, P.E., CARVALHO, J.G. \& BALIEIRO, A.C.Incidência e severidade da cercosporiose do cafeeiro em função do suprimento de potássio e cálcio em solução nutritiva. Fitopatologia Brasileira 28:286291. 2003.

KHALID, R.A. SILVA, J.A. \& FOX, R.L. Residual effects of calcium silicate in tropical soil. I - Fate of applied silicon during five years cropping. Soil Science Society of America Journal 42:8994. 1978.

KORNDÖRFER, G.H. \& GASCHO, G.J. Avaliação de fontes de silício para o arroz. In: Congresso Nacional de Arroz Irrigado, 1., 1999, Pelotas. Anais... Pelotas, 1999. pp.313-316.

MALAVOLTA, E. Elementos de nutrição mineral das plantas. São Paulo. Agronômica Ceres. 1980.

MALAVOLTA, E., VITTI, G.C. \& OLIVEIRA, S.A. Avaliação do estado nutricional das plantas: princípios e aplicações. 2. ed. rev. e atual. Piracicaba. POTAFOS, 1997.

MARSCHNER, H. Mineral nutrition of higher plants. New York. Academic Press, 1995.

MATIELlO, J.B., SANTINATO, R., GARCIA, A.W.R., ALMEIDA, S.R. \& FERNANDES, D.R. Cultura de café no Brasil - Novo manual de recomendações. Rio de Janeiro e Varginha. MAPA/PROCAFÉ - Fundação PROCAFÉ. 2002.

MENZIES, J.G., EHRET, D.L., GLASS, A.D.M., HELMER, T., $\mathrm{KOCH}, \mathrm{C}$. \& SEYWERD, F. Effects of soluble silicon on the parasitic fitness of Sphaerotheca fuliginea on Cucumis sativus. Phytopathology 81:84-88. 1991.

PASCHOLATI, S.F. \& LEITE, B. Hospedeiros: mecanismos de resistência. In: Bergamin Filho, A., Kimati, H. \& Amorin, L. (Eds.) Manual de Fitopatologia - princípios e conceitos. São Paulo. Ceres. 1995. pp.417-453.

POZZA, A.A.A. Silício em mudas de cafeeiro: efeito na nutrição mineral e na suscetibilidade à cercosporiose em três variedades. (Tese de Doutorado). Universidade Federal de Lavras. 2004.

POZZA, A.A.A., ALVES, E., POZZA, E.A., CARVALHO, J.G., MONTANARI, M., GUIMARÃES, P.T.G. \& SANTOS, D.M. 
Efeito do silício no controle da cercosporiose em três variedades de cafeeiro. Fitopatologia Brasileira 29:185-188. 2004.

POZZA, A.A.A., MARTINEZ, H.E.P., POZZA, E.A., CAIXETA, S.L. \& ZAMBOLIM, L. Intensidade da mancha de olho pardo em mudas de cafeeiro em função de doses de $\mathrm{N}$ e de $\mathrm{K}$ em solução nutritiva. Summa Phytopathologica 26:29-34. 2000.

RODRIGUES, F.A., VALE, F.X.R., KORNDÖRFER, G.H., PRABHU, A., DATNOFF, L.E., OLIVEIRA, A.M.A. \&
ZAMBOLIM, L. Influence of silicon on sheath blight of rice in Brasil. Crop Protection 22:23-29. 2002.

RODRIGUES, F.A,. BENHAMOU, N., DATNOFF, L.E., JONES, J.B. \& BÉLANGER, R.R. Ultrastuctural and cytochemical aspects of silicon-mediated rice blast resistance. Phytopathology. 93:535546. 2003

SILVA, D.J. da. Análise de alimentos (métodos químicos e biológicos). Viçosa. Imprensa Universitária. 1981. 